\title{
La Sagrada Escritura en la biblioteca de Juan Funguerio (1546-1612), un calvinista neerlandés de primera hora
}

Holy Bible in Johannes Fungerius Library (1546-1612): a Dutch Calvinist of the beginnings

\section{Beatriz COMELLA-GUTIÉRREZ}

Departamento de Historia de la Educación y Educación Comparada

Universidad Nacional de Educación a Distancia (Madrid)

https://orcid.org/0000-0002-4749-7742

bcomella@edu.uned.es

\begin{abstract}
This paper analyzes the content of the private library of the Dutch humanist Johannes Fungerius, a remarkable bibliophile, consisting of about 1100 titles, according to the public auction document of them, verified in Leiden in 1613 . The set of theological books and especially the copies of the Sacred Scripture will be studied, in order to check if they responded to a Calvinist profile of the beginnings. Everything seems to indicate that they were the books of a northern humanist, a reformed Christian of moderate tendency, with broad intellectual interests.
\end{abstract}

Keywords: Johannes Fungerius; private library; Holy Bible; Calvinism.
Resumen: El artículo analiza el contenido de la biblioteca privada del humanista neerlandés Juan Funguerio (1546-1612) notable bibliófilo, formada por unos 1100 títulos, según el documento de subasta pública de los mismos, verificada en Leiden en 1613. Se estudiarán el conjunto de los libros teológicos y especialmente los ejemplares de la Sagrada Escritura, a fin de comprobar si respondían al perfil de un calvinista de primera hora. Todo parece indicar que fue un humanista del norte, un cristiano reformado de tendencia moderada, con amplios intereses intelectuales.

Palabras clave: Juan Fungerio; biblioteca privada; Sagrada Escritura; calvinismo.

\section{INTRODUCCIÓN}

Johannes Funguerius fue un humanista originario de Frisia, región septentrional de los actuales Países Bajos. Su figura es relativamente poco conocida en su tierra natal y casi ignorado en el resto de Europa, a pesar de pertenecer a una de las generaciones más florecientes del denominado bumanismo del norte ${ }^{1}$. Nació en

1 Cfr. Fokke AKKerman, Arjo VAnderjagt y Adrie VAN DER LAAN (eds.), Northern Humanism in European Context, 1469-1625: From the Adwert Academy to Ubbo Emmius, Leiden, 1999, pp. 134- 
1546, año de la muerte de Lutero, en Leeuwarden y falleció en 1612 en Franeker, una población cercana. Su apellido aparece con diversas variantes en sus obras impresas y en las referencias bibliográficas (Funguerius, Funckeri, Funger, Fongers), por tanto, en las siguientes líneas, para evitar confusiones, se le nombrará como fuan Funguerio, castellanizado.

Realizó los estudios de artes liberales en el Colegio Trilingüe de Lovaina y de medicina e historia en la universidad de Colonia, dos notables centros académicos católicos. Obtuvo además el doctorado en ambos derechos, si bien no se dedicó a la judicatura ${ }^{2}$. Fue, ante todo, un humanista y profesor de escuelas de gramática latina en su Frisia natal; admirador de Cicerón y Séneca, de Plutarco y Quintiliano, seguidor de Agricola, Erasmo y Vives, de Melanchthon y Calvino.

Viajó por Francia donde editó algunas obras; otras vieron la luz en prestigiosas imprentas de los Países Bajos, Imperio germánico e Italia. Fue un gran bibliófilo y hombre pacífico, sin embargo, presenció la rebelión del norte de los Países Bajos contra Felipe II y la instauración de cultos cristianos reformados en torno a 1581; vivió en una época convulsa desde el punto de vista religioso y sumamente creativa en el ámbito cultural.

Funguerio recibió el mismo nombre de pila de su padre, Jan (Johannes), director o rector de la escuela de gramática latina en su ciudad natal. Su madre se llamaba Anna. Es muy posible que la formación familiar marcara al joven Funguerio en el espíritu del humanismo. Se casó con Lutds (Lucrecia), hija de Wybrand van Hallum, filólogo latinista y rector de la escuela de gramática

138; Thomas HAYE, Humanismus im Norden: frühneuzeitliche Rezeption antiker Kultur und Literatur an Nord-und Ostsee, Amsterdam, 2000. El humanismo del norte de Europa hizo especial hincapié en temas relacionados con la religión y la piedad personal; posee unas características propias: en primer término un modelo antropológico basado el hombre interior que busca la relación directa del individuo con Dios, sin mediaciones; en segundo lugar, la asimilación de la cultura grecolatina por influencia italiana desde el punto de vista lingüístico y ético; en tercer lugar, un notable interés de los eruditos por las lenguas hebrea, griega y latina para los estudios bíblicos; en cuarto lugar, el desarrollo de tratados educativos y propuesta de reformas para los studia bumanitatis y la educación universitaria; en quinto lugar, abundancia de literatura sobre educación cívica y pacifismo; por último, el criticismo y las subsiguientes polémicas intelectuales y teológicas. Vid. Olegario NEGRÍN FAJARDO, Fuentes para el estudio del bumanismo pedagógico en Europa, en Historia de la educación: Revista interuniversitaria, 31 (2012), pp. 319-338; Javier VERGARA CIORDIA, Las obras pedagógicas del humanismo erasmista, en Miguel Anxo PEÑA GONZÁlEZ y Inmaculada DELGADO JARA (coords.), Revolución en el humanismo cristiano: La edición de Erasmo del Nuevo Testamento (1516), Salamanca, 2016, pp. 245-277.

2 No obstante, Funguerio se dio de alta en la Corporación de Abogados de Frisia en 1579 y fue jurisconsulto de la Corte de Justicia según recoge Martin H. ENGELS, Chronologische en alfabetische naamlijst, 1577-1849, Leeuwarden, 2007. 
latina de Leeuwarden en 1562. Es decir, siguió profesionalmente a su padre y a su suegro ${ }^{3}$.

Efectivamente, entre 1550 y 1700, en los Países Bajos, el oficio docente se heredaba con frecuencia de padres a hijos; incluso antes de la reforma, muchos eran laicos. Sin embargo, a partir del primer sínodo de Dordrecht (1578), los maestros de las Provincias del norte debían pertenecer a una congregación calvinista, aunque no implicaba el ejercicio de tareas pastorales ${ }^{4}$.

Por lo que se refiere a la tipología escolar, en el nivel secundario de enseñanza, correspondiente a la escuela de gramática latina, desde finales del siglo XVI, se dieron en dicha zona geográfica dos modelos fundamentales: por un lado, el que seguía el prototipo germano, que era mayoritario y preparatorio a la universidad y estaba dirigido a hijos de la burguesía; y, por otro lado, el prototipo francés, para hijos de nobles 5 . Las escuelas regentadas por la familia de Juan Funguerio y, posteriormente, por él mismo, pertenecían al modelo germano.

Funguerio vivió en una etapa de eclosión del humanismo septentrional europeo $^{6}$. Dedicó prácticamente toda su vida a estudiar, enseñar y escribir: es autor de dieciséis obras, la mayor parte poseen carácter filológico: un compendio etimológico trilingüe, odas patrióticas y poemas, además de un tratado de educación para jóvenes ${ }^{7}$. En su conjunto poseen un carácter humanista en el

3 Las fuentes sobre la biografía y obra de Funguerio son: Ranutio GHERO, Delitiae Centum Poetarum Belgicorum, Francoforte, 1614, pp. 428-444; Franciscus SWEERTIUS, Athenae Belgicae sive Nomenclator infer. Germaniae scriptorvm, qvi disciplinas philologicas, philosophicas, theologicas, ivridicas, medicas et mosicas illvstrarvnt, Antuerpiae, 1628; Valerius Andreas DESSELIUS, Fasti Academici Studii Generalis Lovainensis, Lovainii, 1635, p. 503; Thomas CREMIUS, De Eruditione Comparanda In Humanioribus, Vita, Studio Politico, Cognitione Auctorum Ecclesiasticorum, Historicorum, Politicorum ac Militarium, item Peregrinatione tractatus. Foach. Camerarii, Foh. Fungeri, Arn. Clapmarii, Lugduni Batavorum, 1699; Christopher SAXIUS, Onomasticon literarium, t.3, Traiecti ad Rhenum,1784, p.529. Más recientemente: Abraham Jacob VAN DER AA, Biographischwoordenboek der Nederlanden, t. 6, Haarlem, 1852-1878, pp. 273-274 y Philip Christian MOLHUYSEN y Petrus Johannes BLOK, Nieuw Nederlandschbiografisch woordenboek, Leiden, 1918, p. 625.

4 Cfr. Henry Van TiL, The Calvinistic Concept of Culture, Michigan, 2001, p. 215.

5 Cfr. Petrus Theodorus BOEKHOLT y Engelina DE BOOY, Geschiedenis van de school in Nederland vanaf de middeleeuwen tot aan de buidige tijd' door, Assen-Maastricht, 1987, pp. 150-155.

6 Vid. Christian L. HeEsakkers, La difusión del bumanismo en los Países Bajos: desde Erasmo hasta la fundación de las primeras universidades holandesas, en Ferrán GRAU CODINA (coord.), en La Universitat de València i l'bumanisme: Studia humanitatis i renovació cultural a Europa i el nou món, Valencia, 2003.

7 Se titula: De puerorum disciplina et recta educatione liber (Libro sobre la buena enseñanza y educación de los jóvenes, 1584), impresa por Cristóbal Plantino en Amberes y reeditada en Leiden por Francisco Ravelingen, uno de sus yernos, en 1586. Una monografía sobre esta obra puede encontrarse en Juan Funguerio, De puerorum disciplina et recta educatione liber, estudio preliminar de Beatriz COMELLA-GUTIÉRREZ; texto bilingüe latín-castellano y notas a cargo de Virgilio RODRÍGUEZ GARCÍA, Madrid, 2018. 
sentido de tender puentes entre la cultura clásica y el tiempo que le tocó vivir, utilizando especialmente la lengua latina como instrumento. Como buen humanista cultivó el amor a los libros y su biblioteca personal es selectiva: eligió los libros de aquellos autores que consideraba maestros para el cultivo personal ${ }^{8}$.

El presente estudio pretende exponer el contenido de esta biblioteca, compuesta por más de 1100 títulos y vendida en subasta pública en Leiden en 1613, al año siguiente de su muerte ${ }^{9}$. Se hará referencia especial a los libros teológicos y, más concretamente, a los ejemplares de la Sagrada Escritura, con el fin de comprobar la penetración de las doctrinas reformadas en un bibliófilo calvinista de la primera hora. Para contextualizar el objeto de estas líneas, se analizará brevemente la situación religiosa en el norte de los Países Bajos y las principales diatribas teológicas nacidas por entonces en dicha zona.

Desde el punto de vista metodológico, el punto de partida de las siguientes líneas ha sido el estudio monográfico, ya citado, sobre el contexto en que vivió Juan Funguerio y su producción literaria, publicada por la autora de este artículo en la Collectio scriptorum mediaevalium et renascentium del Grupo de Estudios Medievales y Renacentistas (GEMYR) y las editoriales de la Universidad Nacional de Educación a Distancia y la Biblioteca de Autores Cristianos. En este volumen se analizan las fuentes documentales desde el siglo XVI sobre el autor y su época, repertorios bibliográficos y artículos académicos en varias lenguas europeas. Además, se ha contado con el citado catálogo de la subasta de la biblioteca fungueriana, puesta a disposición de los investigadores en la red, una fuente de primera magnitud para su conocimiento y hermenéutica.

La hipótesis inicial ha sido la siguiente: Juan Funguerio volvió a Frisia, en torno a 1577, donde ejerció la docencia en escuelas de latinidad, después de tres lustros de estudios en Lovaina y Colonia. Por entonces, se fraguó la rebelión holandesa o Guerra de Flandes constituida por tres elementos: el afán de parte de la nobleza neerlandesa de independizarse del poder regio hispano, la aspiración de extender los principios religiosos de la Paz de Ausburgo a los territorios del

8 Sobre las bibliotecas privadas de humanistas, vid. Vicente BÉCARES BOTAS, Los libros y las lecturas del bumanista, en Silva: Estudios de bumanismo y tradición clásica, 2 (2003), pp. 9-26.

9 Vid. Veilingcatalogus bibliotheek Fohannes Fungeri, 1613 (Catálogo de la subasta de la biblioteca de Juan Funguerio). Un ejemplar del catálogo original se encuentra en la Kongelige Bibliotek Kopenhagen (Biblioteca Nacional de Dinamarca), con la referencia ms. 79 II 29. Martin H. ENGELS, antiguo curator de la Provinciale Bibliotheek van Friesland (Biblioteca Provincial de Frisia en Leeuwarden) ha publicado una base de datos basada en dicho catálogo: http://www.mpaginae.nl/ At/Fungeruslinks.htm (consultada 22-12-2016). 
norte, bajo el liderazgo del calvinista Guillermo de Orange y la negativa de Felipe II ante estas pretensiones. Estas circunstancias plantean una cuestión abierta: ¿refleja la biblioteca del humanista y bibliófilo Juan Funguerio las corrientes religiosas del tiempo que le tocó vivir?

\section{COORDENADAS RELIGIOSAS Y TEOLÓGICAS EN LOS PAÍSES BAJOS DURANTE EL SIGLO XVI}

El mapa de las confesiones cristianas en los Países Bajos durante el siglo XVI depende de numerosas variables, puesto que la difusión de las nuevas doctrinas no fue uniforme: por una parte, al principio alcanzaron a minorías, en ocasiones pasaron a la clandestinidad, se nutrieron de una notable circulación de libros, panfletos y pasquines; por otro lado, contaron con líderes carismáticos que enardecían a sus seguidores y se alternaron fases de tolerancia con las de violencia, por motivos religiosos ${ }^{10}$.

Desde la perspectiva cronológica, en líneas generales, se puede afirmar que hacia 1520, fecha de la excomunión de Lutero, en Frisia y el resto de las provincias del norte de los Países Bajos hispanos, se había producido una lenta pero progresiva penetración clandestina de diversas ramas de la reforma ${ }^{11}$. Hay testimonios elocuentes sobre la división religiosa, como el temprano testimonio del deán de Leeuwarden, que escribió en 1524: «la gente común simpatiza con Lutero a causa de que los curas y papistas venden bienes espirituales», en clara alusión a las indulgencias ${ }^{12}$.

A partir de 1530, se extiende de modo incipiente la reforma helvética de Zwinglio y la anabaptista de Menno Simons, que fue perseguida tanto por reformados como por católicos; a partir de 1550, la infiltración del calvinismo es un hecho ${ }^{13}$. En cualquier caso, es necesario subrayar que en esta zona de Europa

10 Cfr. Herman Selderhuis (ed.), Handbook of Dutch Chruch History, Göttingen, 2014, pp. 201223.

11 Thomas Martin LiNDSAY, La Reforma y su desarrollo social, Barcelona, 1986, p. 135. No obstante, también eran oriundos de Frisia notables católicos como Pietersz Sjoerd (Petrus Suffridus), jurista, filólogo e historiador 1527-1597), profesor de la Universidad de Colonia; el humanista y diplomático Viglius van Aytta (1507-1577) y Joachim Hoppers (1523-1576) jurista y asesor de Felipe II, que se mantuvieron fieles a Roma.

12 Cfr. Herman SelderHUIS, Handbook of Dutch Chruch History, op. cit., p. 114.

13 Cfr. Paul F. Grendler, Renassaince Education between Religion and Politics, Aldershot, 2006, pp. 75-79. 
existía un caldo de cultivo propicio a partir de la expansión de la devotio moderna, el criticismo de Erasmo y la traducción de la Biblia a lenguas vernáculas ${ }^{14}$.

Por lo que se refiere a la actual de Frisia y otras provincias del norte, las medidas contra el avance de la reforma por parte de las autoridades hispanas se materializaron en la prohibición de libros de autores reformados y en la ejecución de algunos protestantes neerlandeses, entre 1525 y 1531. Por entonces, se prohibió a los laicos predicar o hablar en público sobre la Biblia. La presión de la política religiosa produjo el exilio de neerlandeses no católicos hacia ciudades como Emden, Aquisgrán, Wesel, Francfort y Londres.

La evolución religiosa en los Países Bajos está directamente relacionada, como se ha indicado y es bien conocido, por la revuelta de una parte de los neerlandeses, guiados por el príncipe calvinista Guillermo de Orange-Nassau, contra la corona española, convirtiéndose en una república independiente en $1581^{15}$; mientras que la actual Bélgica, Luxemburgo y territorios franceses, se mantuvieron fieles a Felipe II y la obediencia a Roma ${ }^{16}$. Los intentos diplomáticos de Orange ante la corte de Madrid a fin de conseguir la misma tolerancia religiosa que gozaba el imperio germano desde la Paz de Augsburgo (1555) habían resultado fallidos; el hijo de Carlos V no podía aceptar que una parte de sus súbditos siguieran el camino de la herejía iniciado por Lutero, ni a perder influencia política y económica sobre un territorio tan rico como Flandes.

Tras violentos enfrentamientos por ambas partes, en el norte se inició el desmantelamiento de la Iglesia católica, de manera progresiva, permitiendo algunas minorías de anabaptistas y otros reformados. Concretamente, en Frisia se refugiaron anabaptistas, seguidores de Menno Simons (1496-1561), y el huma-

14 Jacob van Liesvelt (ca. 1489-1545) hijo de impresor Adriaen van Liesvelt, nacido en Amberes. Continuó el trabajo de su padre y se dedicó a imprimir libros de autores católicos y reformados. De sus prensas salió en 1526 la primera Biblia traducida al neerlandés a partir del texto luterano. Fue acusado de comportamiento herético y decapitado en 1545.

15 Carlos V apadrinó a Guillermo de Orange-Nassau (1533-1584), nacido en tierra germana y educado en la fe luterana. Al heredar el título francés de príncipe de Orange con sólo once años, por la muerte sin descendencia su primo Renato de Châlon, el emperador actuó como regente y lo envió a la corte de Bruselas proporcionándole una excelente formación militar, diplomática e instrucción en la fe católica. Guillermo se adhirió al calvinismo en 1573, tras la matanza de hugonotes franceses en la desgraciada noche de san Bartolomé.

16 La independencia de la República de las Provincias Unidas de los Países Bajos, liderada por Guillermo de Orange-Nassau, aunó inicialmente a las provincias del norte como Frisia, Groninga, Holanda, Zelanda, Drenthe, Overijssel, Güeldres, ducado de Brabante, condado de Flandes y obispado de Utrecht. El resto de los territorios, situados al sur, se mantuvieron bajo la corona española (provincias de Namur, Limburgo y Luxemburgo, condado de Henao, y los territorios franceses de Artois y Douai). 
nista de origen polaco Juan Lasco (Jan Lask, 1499-1560), discípulo de Erasmo, marcado teológicamente por Zwinglio, Martín Bucero y Calvino, pero no llegaron a un acuerdo en materia teológica ${ }^{17}$.

\section{BASES TEÓRICAS Y DIFUSIÓN DEL CALVINISMO}

Las bases teóricas del calvinismo en los Países Bajos se originan a partir de 1561, año en que Guido de Brès colocó en la muralla de la ciudadela de Tournai (Bélgica) su Confesión de fe o Confessio belga ${ }^{18}$. Poco tiempo más tarde, en 1566, se tradujo al neerlandés el Catecismo de Heidelberg: ambos documentos son la base del calvinismo neerlandés. La primera reunión de esta confesión se celebró en 1571 y tuvo lugar en territorio germano, en la ciudad de Emden, de modo clandestino. Fue liderada por Marnix de St. Aldegonde, exalumno de la Academia de Ginebra y partidario de Guillermo de Orange ${ }^{19}$. Los asistentes se pusieron de acuerdo para admitir, en primer lugar, la Confessio belga (37 artículos del Credo, basado en la Biblia protestante, la doctrina de Calvino y algunos autores católi-

17 Cfr. Francisco LIMÓN (ed.), Introducción a la Historia de la Iglesia reformada, Florida, 2012, pp. $102-$ 104.

18 Guy de Brès (o de Bray), líder de las ideas reformadas de los Países Bajos, nació en Mons, Francia, en 1522 y murió ejecutado en Valenciennes el 31 de mayo de 1567. Entre los calvinistas se le considera mártir. Su familia era de gran tradición católica, pero el joven Guy entró en contacto con las ideas reformadas a través de los libros. Fue alumno de Calvino y Beza en Ginebra. Tuvo que huir a Inglaterra, donde fue coincidió con otros extranjeros reformados y refugiados por motivos religiosos en la isla durante el reinado de Eduardo VI (1537-1553).

Brès fundó una congregación reformada en Lieja y pasó gran parte de su vida como predicador huyendo de un sitio a otro. Su Confesión belga está basada en la de los calvinistas franceses y ginebrinos, redactada por Calvino. Fue escrita como defensa ante Felipe II, para demostrar que los creyentes reformados no eran rebeldes, sino ciudadanos respetuosos de las leyes que profesaban según las enseñanzas de la Sagrada Escritura. La Confesión belga no tuvo efecto positivo sobre las autoridades españolas; sin embargo, sirvió también como medio de instrucción de los calvinistas neerlandeses. Cfr. Philippe SCHAFF, The creeds of Christendom, Michigan, 1931, pp. 676-677.

19 Philippe de Marnix, barón de Sainte Aldegonde nació en 1540 en Bruselas y murió el 15 de diciembre de 1598 en Leiden. Fue estadista y soldado, teólogo y maestro. Escribió en tres idiomas: neerlandés, francés y latín. Probablemente estudió derecho en Lovaina, París y Padua y teología en Ginebra con Juan Calvino y Beza. Volvió al sur de los Países Bajos hacia 1561. A partir de 1565 apoyó a Guillermo, príncipe de Orange-Nassau en la organización de revueltas contra Felipe II. Con la llegada del duque de Alba a Bruselas en 1567, Marnix se vio obligado a abandonar el país y encontró refugio en Bremen; desde allí preparó el sínodo de Emden, primera reunión de congregaciones calvinistas de los Países Bajos, Francia y el Imperio alemán. También participó en el primer sínodo de Dordrecht (1578). 
cos como san Agustín). En segundo lugar, mostraron su adhesión al Catecismo de Heidelberg escrito por dos jóvenes discípulos de Lutero y Melanchthon en 1563, formado por 129 preguntas y respuestas y, en tercer lugar, los cánones de sínodo propiamente dicho ${ }^{20}$. Posteriormente, se unieron a estos postulados las conclusiones del primer sínodo de Dordrecht o Dordt (1578) celebrado en territorio neerlandés, si bien otro sínodo más relevante desde el punto de vista histórico, se celebró en la misma ciudad en 1618-161921.

Por lo que respecta a Frisia, se pudo celebrar una reunión sinodal en mayo de 1580 en Sneek, ciudad situada al suroeste de Leeuwarden, a la que asistieron los pastores y maestros. Desde entonces quedó prohibido el culto público católico. La situación había cambiado radicalmente: los Estados Generales, de confesión calvinista, ilegalizaron la Iglesia católica, pasando ésta a ser una secta de la superstición papista hasta inicios del siglo XVII. Desde entonces, en Frisia fue disminuyendo la población católica, que en torno a 1650 era el $10 \%$ del total. La falta de sacerdotes, sobre todo en zonas rurales, facilitó la agonía del catolicismo ${ }^{22}$.

Los bienes eclesiásticos, pasaron a manos de los Estados Generales, tras la prohibición del culto público católico sirvieron, durante una década, para sufragar los gastos militares y, posteriormente, para el mantenimiento de los pastores

20 Texto de la Confesión belga y del Catecismo de Heidelberg en castellano: http://www.iglesiapueblonuevo.es (consultada17-5-2017). El Catecismo de Heidelberg recibió su nombre del lugar de su impresión, Heidelberg, capital del Palatinado. Allí, con el fin de que la fe reformada se pudiera mantener en su dominio, el príncipe elector Federico III encargó dos discípulos de Melanchthon y Calvino, Zacarías Ursino, profesor de la Universidad de Heidelberg y a Gaspar Olevianus, predicador de la corte, la preparación de un manual para la enseñanza catequética. De esta iniciativa surgió el Catecismo, que fue aprobado por el propio elector y por el Sínodo de Heidelberg y publicado por primera vez en 1563 . Está dividido en 129 preguntas y respuestas a explicar en los 52 domingos del año. En 1566 fue traducido al neerlandés. Cfr. Gerald NYENHUIS, Comentario del Catecismo de Heidelberg, México D.F., 2004.

21 El sínodo estableció la doctrina reformada en cinco puntos: depravación total, elección incondicional, expiación limitada, vocación eficaz (o gracia irresistible) y perseverancia de los santos. En dicho sínodo, Francisco Gomarus, calvinista apoyado por Mauricio de Orange-Nassau, rebatió la doctrina moderada de Jacobo Arminio, dando lugar a la división entre gomaristas y arminianos. Cfr. Donald SINNEMA, Calvin and the Canons of Dordt (1619), en Church History and Religious Culture, 91 (2011), pp. 87-103. Sobre los sínodos de Emden y Dordrecht (en textos en inglés Dordt); se puede ver la traducción española: http://www.iglesiapueblonuevo.es/index.php?codigo=enc_reformadah (consultada 17-5-2017)

22 Cfr. Charles H. PARKER, Faith on the margins: catholics and Catbolicism in Dutch golden age, Massachusetts, 2008, p. 29; Geert H. JANSSEN, The dutchness of the Dutch Golden Age, en The Historical fournal, 53/3 (2010), pp. 805-817. 
calvinistas, las iglesias confiscadas y obras de caridad. Solo en Frisia había, por entonces, 63 conventos y monasterios y 360 parroquias.

En esta etapa quedaron prohibidos los actos de culto públicos (misa, procesiones), la catequesis y las imágenes. También hubo ejecuciones: de sacerdotes y religiosos en Gorcum, Almaark y Limburgo. Muchos fueron encarcelados y quedaban libres, sin poder ejercer su ministerio, tras pagar importantes multas: fue el caso de Petrus Cuneris, segundo obispo de Leeuwarden que, tras ser privado de libertad, tuvo que abandonar la ciudad en $1579^{23}$. Más adelante, en vista de la situación, la Santa Sede creó el Vicariato apostólico de Batavia en 1592, con el fin de encargarse del cuidado pastoral de los católicos holandeses, que se mantuvo activo hasta la restauración de la jerarquía católica en 1853 . El papa Clemente V y sus sucesores contaron con el apoyo de los jesuitas en la difícil misión de apoyarles pastoralmente.

Tras un somero repaso sobre el horizonte histórico y religioso en que vivió el humanista Funguerio, estamos en condiciones de conocer los libros que le acompañaron.

\section{LA BIBLIOTECA DEL HUMANISTA NEERLANDÉS JUAN FUNGUERIO}

Cabe plantearse, en primer lugar, cómo pudo adquirir una biblioteca de más de 1100 títulos e índole cualitativa, un director y docente de una escuela de latinidad de la remota Frisia ${ }^{24}$. Como hipótesis, es factible que llegaran a él por varias vías: donación o herencia de su padre y de su suegro; regalos de sus mecenas (varias familias de la nobleza terrateniente local); pago en especie por sus propias obras; obsequios de sus editores; remuneración como corrector de pruebas de imprenta de libros que exigían conocer, además del latín, griego y hebreo; adquisiciones propias. Asimismo, es necesario subrayar que nació, estudió y trabajó en una de las zonas de Europa con mayor número de imprentas ${ }^{25}$.

23 Cfr. Neerlandia cathólica seu provinciae ultrajectencis historia et cognitio, Utrecht, 1887. La diócesis de Leeuwarden, sufragánea de Utrecht fue creada en 1559. Su primer obispo fue Remigius Driutius (1561-1569).

24 Según un estudio ya clásico, en el siglo XVI, únicamente los miembros de la alta nobleza civil o eclesiástica, además de los banqueros y mecenas, poseían bibliotecas de unos 1000 títulos; bastantes médicos, hombres dedicados a la carrera política o administrativa solían tener una media de 500; los profesores, artistas y artesanos cualificados, podían sumar entre 100 y 500 ejemplares. Cfr. Juan Carlos GALENDE DíAZ, Las bibliotecas de los bumanistas y el Renacimiento, en Revista general de información y documentación, 6 (1996/2), p. 115.

25 Se calcula que en Europa se imprimieron hasta 1501 unos 30.000 títulos con una tirada de 20 millones de ejemplares: el $37 \%$ en Italia, el 33\% en regiones alemanas, el 17\% en Francia, el 
Como se ha indicado, ha llegado hasta nosotros el contenido de su biblioteca privada antes de su pública subasta; a tal efecto, el librero Juan Olers de Leiden editó un catálogo de los libros, en cuarto de folio, con un total de 80 páginas $^{26}$. En la portada aparecen los siguientes datos:

Cathalogvs Bibliothecae Instructissimae Doctissimi \& Viri D. Ioannis Fungeri, I.V. Doct. \& Gymnasii Franekerani Moderatoris, quae auctione distrahetur in Officina Ioannis Orlers Bibliopolae, in vico de S. Pieters Chom-Steegh. Lvgdvni Batavorvm 22 may. Anno 1613. Stylo Nouo. Excudebat Henricus Ludouici ab Haestens $^{27}$.

Aunque desconocemos si Juan Funguerio y su esposa Lucrecia tuvieron hijos (no hay noticias sobre este particular), parece que ninguno se dedicó a la enseñanza en escuelas de latinidad (como su padre o sus abuelos) ni a la judicatura (Funguerio fue doctor en ambos derechos). Esta circunstancia puede explicar que su biblioteca privada fuera subastada poco después de su fallecimiento. Otra posibilidad, es que no tuvieran descendencia, y su viuda pudiera vivir de las rentas tras la subasta, práctica frecuente en ciudades universitarias de la zona, como Lovaina y Leiden ${ }^{28}$.

Desde el punto de vista cuantitativo, partiendo de la base de datos publicada en la red por Martin H. Engels y tomando como criterio la temática, el número y porcentaje de los libros es como sigue:

7\% en los Países Bajos y el 6\% en otros. Por entonces había unas 1700 imprentas en 300 ciudades. Las más antiguas de los antiguos Países Bajos se instalaron en torno a 1470 en Utrecht, Delft, Gouda, Deventer, Zwolle, Aalst, Lovaina, Brujas y Bruselas. En la década de 14801490 inician su trabajo las de Haarlem, Leiden, Hertogenbosch, Amberes y Gante. http://www. bibliopolis.nl/ (consultada 28-4-2017). Bibliopolis Website van de Koninklijke Bibliotheek te Den Haag over de geschiedenis van de boekdrukkunst in Nederland (Página web de la Biblioteca Real de La Haya sobre la historia de la imprenta en los Países Bajos). En dicha Biblioteca se conservan 2000 incunables.

26 Vid. Veilingcatalogus bibliotheek fohannes Fungeri, 1613 (Catálogo de la subasta de la biblioteca de Juan Funguerio): http://www.mpaginae.nl/At/Fungeruslinks.htm (consultada 22-12-2016).

27 «Catálogo de la Biblioteca del muy instruido y muy docto señor Juan Funguerio, doctor en ambos Derechos y director de la escuela de latinidad de Franeker, cuya subasta al por menor se celebrará en el taller del librero Juan Orlers, en el barrio de san Pedro, cuesta del Coro. 22 de mayo año 1613. Impreso en estilo nuevo por Enrique Luis de Haestens».

28 David MCKITTERICK, The Invention of Rare Books: Private Interest and Public Memory (1600-1840) Cambridge University Press, Cambridge, 2018, p. 336. 


\section{Tabla 1}

\begin{tabular}{|c|c|c|}
\hline Temática & Número de títulos & Porcentaje \\
\hline Teología & 208 & 18,00 \\
\hline Derecho & 77 & 6,66 \\
\hline Política & 27 & 2,33 \\
\hline Medicina & 106 & 9,17 \\
\hline Quadrivium & 34 & 2,94 \\
\hline Historia, Poesía, Filosofía y Lógica & 280 & 24,28 \\
\hline Filología & 256 & 22,16 \\
\hline Miscelánea & 167 & 14,46 \\
\hline Total & 1.155 & $100 \%$ \\
\hline
\end{tabular}

Esta división, publicada en diciembre de 2015 , no plantea en principio problemas, por lo que se refiere a los libros teológicos, jurídicos y médicos, es decir, a los estudios universitarios de la época, que se cursaban tras superar el bachiller en artes $^{29}$. Tampoco ofrece dudas en lo que concierne a la sección miscelánea o a las materias relacionadas con el quadrivium clásico. Sin embargo, no parece adecuado situar, en un mismo epígrafe, los títulos sobre historia, poesía, filosofía y lógica, además de otorgar categoría propia a los títulos de temática política (más relacionados con el derecho o con la filosofía política) y filológica (subdivisión a la que habría que añadir los libros poéticos). Por tanto, se consideran no exactos los criterios aplicados por Martin H. Engels, por no adecuarse totalmente al currículo medio y superior de finales del siglo XVI.

Efectivamente, de acuerdo con el modelo ideal de la bumanitas romana (vir bonus dicendi peritus) y su correlato en los planes de estudios de las escuelas de latinidad de entonces, la imitación de los modelos clásicos mayores se iniciaba con varios años de gramática latina y fundamentos de griego; el currículo preveía además un curso de retórica y otro de oratoria, en los que textos poéticos, históricos o políticos grecolatinos, servían de instrumento para cimentar las bases de una enseñanza humanista. Tras la escuela de latinidad, el bachiller en artes o filosofía, comprendía fundamentalmente el estudio de la lógica, física (clásica y filosofía de la naturaleza) y metafísica, como primer grado de los estudios universitarios. 
Otro aspecto a comprobar es si el conjunto responde a la preparación universitaria y dedicación profesional del dueño de la biblioteca. En la siguiente tabla, se han reagrupado las materias de acuerdo con el currículo de entonces y ordenado de mayor a menor, a fin de mostrar el peso específico de cada bloque de disciplinas:

Tabla 2

\begin{tabular}{lc}
\hline Temática títulos & Porcentaje \\
\hline Filología & 27 \\
\hline Teología & 18 \\
\hline Filosofía & 13,21 \\
\hline Miscelánea & 14,46 \\
\hline Medicina & 9,17 \\
\hline Derecho y Política & 8,99 \\
\hline Historia & 6,23 \\
\hline Quadrivium & 2,94 \\
\hline
\end{tabular}

Con la reordenación de los libros, se aprecia con claridad que Juan Funguerio guardaba en su biblioteca volúmenes que respondían principalmente a cuatro pautas:

a) Sus estudios universitarios en artes, medicina, historia y ambos derechos $(37,6 \%)$.

b) La densa formación filológica propia de un humanista exalumno del Colegio Trilingüe de Lovaina y de un docente de escuela de latinidad $(27 \%)^{30}$.

30 Los autores clásicos y humanistas más admirados por Funguerio ocuparon anaqueles de su biblioteca e inspiraron directamente al autor: se cuentan referencias directas (libros originales) o indirectas (comentaristas) de Cicerón (28), Séneca (4) Quintiliano (2), Plutarco (8); Rodolfo Agricola (3), Erasmo (16), Vives (7), Melanchthon (6), Calvino (12). Efectivamente, en calidad de rector y docente de escuelas de gramática, Juan Funguerio escribió un tratado de educación: De puerorum disciplina et recta educatione liber (Libro sobre la buena enseñanza y educación de los jóvenes, Plantino, Amberes, 1584); dedica los capítulos 7-13 a trazar un plan de estudios para sus estudiantes y se puede comprobar que en su biblioteca se encontraban obras de los autores citados en el currículo. Vid. Fuan Funguerio. Tratado de la buena enseñanza y educación de los jóvenes (1584), op. cit., pp. $155-190$ y $272-291$. 
c) Los intereses amplios de un intelectual de finales del siglo XVI, antes de la eclosión de las ciencias experimentales en la centuria siguiente (miscelánea y quadrivium) $(18,61 \%)$.

d) El aprecio por la Sagrada Escritura en sus lenguas originales y por la literatura patrística, además de la intensidad de las controversias religiosas y teológicas de su época (18\%).

Además, Funguerio poseía cuatro incunables de autores que unen la tradición grecolatina con el humanismo: obras de Aristóteles comentado por Averroes, Salustio, Boecio y Marsilio Ficino ${ }^{31}$.

\section{LA BIBLIOTECA TEOLÓGICA DE JUAN FUNGUERIO}

Antes de analizar los libros teológicos de la biblioteca del humanista y, más concretamente sus ejemplares de la Sagrada Escritura, conviene hacer algunas precisiones relativas a las características externas de los volúmenes y a los criterios utilizados en su estudio ${ }^{32}$.

Atendiendo a la clasificación por tamaño, su biblioteca teológica, compuesta por un total de 208 títulos, contaba con 48 títulos in folio, 46 in quarto, 93 in octavo y 21 in decimosexto.

Por lo que se refiere a la tipología, se ha optado por las siguientes categorías que responden al criterio de autoría, etapa cronológica y número de títulos: $\mathrm{Bi}$ -

31 Los títulos y datos de edición son: Opus Aristotelis Latine, cum Commentarijs Averrois, Venetijs, cura Bernardi de Tridino, An. 1489; Gaius Sallustius Crispus, Salustius cum Commentarijs, Ascensu familiaris, cum plurimis \& intinctis alijs tractatibus. Lugduni, a Stephano Gueinaro, An. MD; Severinus Boetius, De consolatione Philosophiae, Deventer, Richardus I. Pafraet, 1495; Epistolae Marcilii Ficini Florentini, Neurenberg per Antonium Roberger, Anno 1497.

32 Desde el punto de vista del formato, como es sabido, los parámetros generales del tamaño de los volúmenes editados en esa época era el siguiente: en el in-folio (del latín in folio, en hoja) la hoja impresa se doblaba sólo una vez sobre el lado menor, por lo que da lugar a dos folios que equivalen a cuatro páginas. Cuando la hoja se pliega en cuatro, se obtiene un formato in-quarto; si en 8 , in-octavo; si en 16, in-decimosexto, etc. El in-folio será más o menos grande dependiendo de la hoja de papel. Sobre todo, durante el período de impresión manual, las hojas de papel se fabricaban en diversos tamaños que dependían del país, el taller o la fecha. Así, el tamaño de la altura de la página puede variar entre 30,49 y 38,1 centímetros, siendo su valor medio de $34 \mathrm{~cm}$. Las equivalencias de los siguientes tamaños menores era la siguiente: quarto $26 \mathrm{~cm}$, octavo $18 \mathrm{~cm}$, decimosexto $12 \mathrm{~cm}$ de alto.

Parece que el tamaño decimosexto, equivalente a un libro de bolsillo, fue puesto en circulación por el impresor lionés Guillaume Rouille. Vid. José Luis CHECA CREMADES, Encuadernación. Doce ensayos sobre bibliofilia y artes del libro (siglos XIV-XXI), vol. 1, Madrid, 2012, pp. 15-27. 
blia (completa) y Nuevo Testamento ${ }^{33}$, Padres de la Iglesia, autores medievales, autores coetáneos católicos y reformados ${ }^{34}$. En la siguiente tabla se da cuenta de la proporción y peso específico de cada una.

Tabla 3

\begin{tabular}{lcccc}
\hline Biblioteca teológica & $\begin{array}{c}\text { Número de } \\
\text { autores }\end{array}$ & Porcentaje & $\begin{array}{c}\text { Número } \\
\text { de títulos }\end{array}$ & Porcentaje \\
\hline Sagrada Escritura & $15^{*}$ & 10,41 & 15 & 7,21 \\
\hline Padres de la Iglesia & 23 & 15,97 & 31 & 14,90 \\
\hline Autores medievales & 9 & 6,25 & 9 & 4,32 \\
\hline Autores modernos católicos & 31 & 21,52 & 38 & 18,26 \\
\hline Autores modernos reformados & 66 & 45,83 & 115 & 55,28 \\
\hline$\quad$ Totales & 144 & 100,00 & 208 & 100,00 \\
\hline
\end{tabular}

* En este caso, se trata de ediciones distintas.

Según estos datos, se puede colegir que los libros de Funguerio se corresponden a la perfección con el perfil de un humanista reformado: su interés por la Sagrada Escritura y los Padres de la Iglesia, el volumen de libros de autores cristianos reformados y su escaso aprecio por ámbito medieval y católico coetáneo, resultan reveladores sobre su identidad cultural y religiosa.

En números absolutos, los dos autores más frecuentes en esta biblioteca son Calvino y Joannes Drusius ${ }^{35}$. Estos datos resultan esclarecedores si se tiene en

33 Los comentarios a libros de la Biblia y demás estudios bíblicos se colocan en la etapa correspondiente al autor.

34 Casos paralelos se encuentran en las bibliotecas privadas de otros coetáneos calvinistas, que también fueron vendidas en pública subasta: Catalogus librorum bibliothecae nobilissimi clarissimique viri piae memoriae D. Philippi Marnixii Sancto-Aldegondii. Leiden: Gujot, 1599; Veilingcatalogi, Particuliere bibliotheken, Canterus, Theodorus, Lugduni Batavorum: Elzevir,1617 y Catalogvs librorvm, qui ex bibliotheca reverendi \& celeberrimi viri, D. Sibrandi Lvbberti, p.m. SS. Th. dum viveret, Doctoris \& Professoris primarii in Acad. Franekerana, publica auctione Franekere distrabentur 29 die Augusti 1625, exudebat Fredericus Heynsius Typographus in Academiâ Franekerana, Franekeræ, 1625.

35 Johannes Drusius (nombre latinizado de Jan van den Driesche) (1550-1616) orientalista flamenco, fue docente en prestigiosas universidades inglesas; tras la pacificación de Gante (1576), volvió a los Países Bajos e impartió clases en la Universidad de Leiden y, desde su fundación en 1585, en la de Franeker (Frisia), donde pudo conocer a Juan Funguerio. 
cuenta que Funguerio fue un calvinista de primera hora, pero de talante moderado, más cercano a las posturas de Jacobo Arminio y sus seguidores ${ }^{36}$.

Además, parece claro que, para su nutrida biblioteca teológica, Juan Funguerio había adquirido o seleccionado pocas obras, pero de un amplio número de autores contemporáneos, es decir, parece que su intención podría centrarse en lecturas selectas de un nutrido grupo de coetáneos, vinculados al cristianismo reformado.

\section{LA SAGRADA ESCRITURA EN LA BIBLIOTECA FUNGUERIANA}

Desde el siglo IV, la Biblia Vulgata de san Jerónimo, patrocinada por el papa san Dámaso, tomó carta de naturaleza en toda la Cristiandad occidental. Hasta entonces circulaban diversas versiones de la denominada Vetus latina, con frecuencia demasiado literales y de calidad variable. El traductor de Estridón, seguidor de Cicerón en su elegancia y claridad, expurgó textos, buscó los mejores códices hebreos y griegos para obtener una versión latina no literal, pero fiel a los originales y, sobre todo, al sentido de los pasajes ${ }^{37}$.

Sin embargo, la Vulgata sufrió, a lo largo de los siglos medievales, notables alteraciones y variantes, en parte debido a su copia manuscrita y a la pérdida de versiones antiguas. Desde el siglo $\mathrm{X}$, hubo diversos intentos de rescatar la versión original de san Jerónimo, purificándola de adherencias y errores por iniciativa, entre otros, de los camaldulenses de san Pedro Damián y los cistercienses guiados por san Esteban Harding. Más adelante, se publicaron diversos Correctorios,

36 Jacobo Arminio (nombre latinizado de Jacob Harmenzoon) (1560-1609) conocido como el fundador de la escuela anticalvinista en la teología protestante reformada, prestando así su nombre a un movimiento (arminianismo) en los Países Bajos. Estudió teología en Leiden y Ginebra. Ejerció como predicador en Amsterdam durante tres lustros. Su interpretación de la epístola a los Romanos, divergente de la ortodoxia calvinista, le llevó a trasladarse a Leiden para obtener en doctorado e impartir clases de teología a partir de 1603 . Desde entonces, como se ha apuntado, se enfrentó a otro profesor, Francisco Gomarus, que defendía la postura calvinista pura sobre la predestinación. La disputa entre arminianos y gomarristas se trasladó a toda la universidad y fue llevada a un diálogo público. Su postura, más cercana a Lutero, se basa en la predestinación condicional y subraya la importancia de la fe, sin negar la omnipotencia divina, la libre voluntad del hombre y el pecado. Los seguidores de Arminio manifestaron sus ideas en una obra titulada Remonstrantice, por ese motivo, también se les denomina remonstrantes. En el segundo Sínodo de Dordrecht (16181619) se consideró herética su teología y se fijaron los cinco puntos del calvinismo.

37 Sobre la obra traductora de san Jerónimo y su pervivencia, Vid. Antonio GarCía Moreno, San Ferónimo, traductor paradigmático, en Scripta Theologica, 11/3 (1979), pp. 889-928. 
con la misma finalidad, si bien no siempre consiguieron su objetivo ${ }^{38}$. En los siglos XIV-XV, «la Vulgata seguía teniendo prestigio, siendo aceptada de modo casi unánime y universal. Pero al mismo tiempo, se había creado un ambiente de desconfianza ante las copias existentes, no siempre tan fieles como era de desear a la versión original del Doctor Máximo» ${ }^{39}$.

La difusión del humanismo propició el estudio de las lenguas bíblicas y el afán por revisar el texto de la Vulgata tanto entre los reformados como entre los católicos. Por otra parte, con la invención de la imprenta, las ediciones se habían multiplicado, pero se siguió reproduciendo versiones poco cualificadas. Otro problema apareció en torno a 1500: en numerosas Biblias publicadas en Lyon, París, Amberes, Basilea y Venecia, las anotaciones a las nuevas ediciones mostraban doctrinas heterodoxas de carácter reformado. Para paliar esta situación, la universidad de Lovaina sacó a la luz su primer Índice de Biblias en 1546 y el Concilio de Trento ordenó la revisión de la Vulgata y en 1564 aparecía el primer Index romano.

En el ámbito del humanismo del norte, desde Agricola, Erasmo y Vives, pasando por Lutero, Melanchthon y Sturm, Calvino y Farel, Budé y Rabelais, hasta Linacre, Colet y Moro, se hizo hincapié en el conocimiento de aquellas lenguas (hebreo, griego y latín) que habían sido el vehículo para expresar las verdades más altas y sagradas. Además, en el ámbito pedagógico, subrayaron el uso de la Sagrada Escritura como medio de formación cristiana: niños y niñas debían aprender a leer para conocer de primera mano desde pequeños la Palabra de Dios, como testimonio vivo del Espíritu Santo en cada individuo ${ }^{40}$.

En el caso del calvinismo, con notable influencia en el norte de los Países Bajos desde 1550, la Sagrada Escritura debía adquirir gran peso específico en la educación de los niños y jóvenes. Los saberes podían obtenerse, según Calvino, por el estudio de los clásicos, de la historia y de la naturaleza; sin embargo, debido a la caída original, el ser humano no estaba capacitado para llegar al verdadero conocimiento de Dios o del mundo, sin la regeneración, que hace posible captar el significado de la Escritura, y sitúa al hombre en la perspectiva apropiada ${ }^{41}$.

38 Cfr. Antonio García Moreno, La Biblia en torno a Trento, en Scripta Theologica, 15/2 (1983), pp. 567-585.

39 Ibid., p. 572.

40 Vid. Juan Calvino, Institución de la religión cristiana, cap. I, 4. Se cita la primera traducción castellana del reformado español Cipriano DE VALERA, Institución de la religión christiana; compuesta en quatro libros, y dividida en capitulos por Iuan Calvino. Y ahora nuevamente traduzida en romance castellano, por Cypriano de Valera, Londres, 1597.

41 Vid. Marta GARCÍA ALONSO, Una ética para los cristianos: el fundamento bíblico de la moral calvinista, en Revista Española de filosofía Medieval, 13 (2006), pp. 165-180. 
Propuso dos niveles de escuela: uno básico, en el que enseñara en lengua vulgar el catecismo, lecto-escritura, aritmética e historia y otro de enseñanza media, dedicada a los estudios de lenguas bíblicas ${ }^{42}$.

Para un ex alumno del Colegio Trilingüe de Lovaina y humanista reformado como Juan Funguerio, la Biblia era la Palabra de Dios, para su lectura y meditación y un monumento de las culturas semita y cristiana antiguas. En este contexto conviene estudiar la Sagrada Escritura en la biblioteca fungueriana ${ }^{43}$.

Antes de morir, el humanista tenía en su haber, además de las citadas Biblias en neerlandés y francés, seis Biblias, un Antiguo Testamento y seis versiones del Nuevo Testamento, datados en un arco de tiempo de edición muy amplio (entre 1537 y 1609). Por lo que se refiere a la ciudad de impresión, Amberes, Basilea y Ginebra van a la cabeza, con tres títulos cada una, seguidas por Lyon y Leiden (uno cada una); de algunos libros se desconoce tanto el traductor y como el lugar de edición.

Inicialmente, la plaza de impresión no aporta datos sobre la confesión religiosa de los editores y compradores de Biblias, puesto que de las citadas prensas salían libros tanto católicos como reformados; sin embargo, cuanto más tardía sea la impresión y más septentrional sea la plaza de edición, es más probable que se trate de un libro no católico. Sin embargo, desde fechas tempranas, las ediciones bíblicas constituyeron motivo de fricción entre católicos y reformados; algunas resultaron controvertidas e incluso rechazadas. Los motivos, como se ha señalado, no fueron tanto las versiones en lenguas bíblicas, sino las anotaciones de las mismas, realizadas desde una óptica más bien católica o reformada.

En la siguiente tabla, se consignan las Biblias completas y ejemplares del Nuevo Testamento, propiedad de Funguerio. Se transcriben los datos del catálogo de la subasta de su biblioteca, tal y como aparecen en el mismo, es decir, la ordenación de los títulos sigue únicamente un criterio de tamaño (de folio a decimosexto), separando, eso sí, las Biblias completas del Nuevo Testamento.

42 Vid. Carl R. TRueman, The Reception of Calvin: Historical Considerations, en Church History and Religious Culture 91 (2011), pp. 19-27.

43 La Biblia (Antiguo Testamento, a partir de la Vulgata) más antigua traducida al neerlandés data de 1477, fue publicada en Delft por Jacob Jacobsz van der Meer y Mauricius Yemantsz. En 1522, Doen Pietersoen publicó en Amsterdam el evangelio de san Mateo, basado en la traducción latina de Erasmo; al año siguiente, el mismo impresor editó la primera traducción al neerlandés del Nuevo Testamento completo, a partir de la versión alemana luterana y en 1526, Jacob van Liesvelt, como se ha indicado, publicó en Amberes la Biblia completa en neerlandés a partir de varias fuentes (Vulgata, Lutero, Ecolampadio).

Sobre la Biblia en la cultura neerlandesa: http://www.bijbelencultuur.nl/(consultada 13-5-2017). Juan Funguerio poseía, además de las citadas, dos versiones en lenguas vernáculas: un ejemplar de la Biblia neerlandesa (Een Duitschen Bijbel) publicada en Dordrecht en 1591 y un Nouveau Testament editado en La Rochelle (Francia) el mismo año, ambos libros in octavo. 


\section{Tabla 4}

\begin{tabular}{|c|c|c|c|c|}
\hline Título & Año & Ciudad/ impresor & Formato/vols. & Traductor \\
\hline $\begin{array}{l}\text { Biblia Sacra, Hebraicè, } \\
\text { Chaldaicè, Graecè \& } \\
\text { Latinè, studio Philippi } \\
\text { Secundi Regis Catholici }\end{array}$ & $\begin{array}{l}1564^{*} \\
1573\end{array}$ & $\begin{array}{l}\text { Antverpiae } \\
\text { Christophorus } \\
\text { Plantinus }\end{array}$ & $\begin{array}{l}\text { folio } \\
\text { vols. } 4^{* *}\end{array}$ & $\begin{array}{l}\text { Arias Montano } \\
(1527-1598)\end{array}$ \\
\hline $\begin{array}{l}\text { Biblia Graeca, cum Caes. } \\
\text { Majest. privilegio impressa }\end{array}$ & 1545 & $\begin{array}{l}\text { Basileae } \\
\text { Johannes Hervagius }\end{array}$ & folio & Sin datos \\
\hline $\begin{array}{l}\text { Biblia Hebraica, } \\
\text { interliniaria ex } \\
\text { interpretatione Pagnini, \& } \\
\text { Testamentum Montani }\end{array}$ & 1609 & Genevae & folio & $\begin{array}{l}\text { Santes Pagnini } \\
(1470-1541) \\
\text { Arias Montano } \\
(1527-1598)\end{array}$ \\
\hline $\begin{array}{l}\text { Biblia Sacra cum brevibus } \\
\text { Annotationibus, cum Indice } \\
\text { Epist. \& Evang. totius anni, } \\
\text { \& cum Indice rer. \& verb. } \\
\text { utriusq; Test. }\end{array}$ & 1537 & $\begin{array}{l}\text { Antverpiae } \\
\text { Ex offic. Ioan. } \\
\text { Steelsij }\end{array}$ & quarto & Sin datos \\
\hline $\begin{array}{l}\text { Totum Vetus Test. vel Biblia } \\
\text { Hebraicè, }\end{array}$ & $\begin{array}{l}\text { Sin } \\
\text { datos }\end{array}$ & Sin datos & $\begin{array}{l}\text { decimosexto } \\
\text { vols. } 4\end{array}$ & Sin datos \\
\hline $\begin{array}{l}\text { Testamentum Bezae Graece } \\
\& \text { Latine, cum quibusdam } \\
\text { Symbolis in fine additis }\end{array}$ & 1555 & $\begin{array}{l}\text { Genevae } \\
\text { Excud. Henricus } \\
\text { Stephanus } \\
\end{array}$ & quarto & $\begin{array}{l}\text { Theodorus Bezae } \\
(1519-1505)\end{array}$ \\
\hline $\begin{array}{l}\text { Laurentij Vallae opera } \\
\text { omnia, praeter annot. in } \\
\text { Novum Testamentum }\end{array}$ & $\begin{array}{l}\text { Sin } \\
\text { datos }\end{array}$ & $\begin{array}{l}\text { Basileae, apud } \\
\text { Sebast. Henr. } \\
\text { Petrum } \\
\end{array}$ & folio & $\begin{array}{l}\text { Laurentius Valla } \\
(1405-1457)\end{array}$ \\
\hline $\begin{array}{l}\text { Novum Test. Graece, cum } \\
\text { Indice }\end{array}$ & $\begin{array}{l}\text { Sin } \\
\text { datos }\end{array}$ & $\begin{array}{l}\text { Basileae } \\
\text { Per Ioannem } \\
\text { Oporinum. }\end{array}$ & decimosexto & Sin datos \\
\hline $\begin{array}{l}\text { Novum Test. Latine, } \\
\text { versum per D. Erasmum } \\
\text { Roterd. }\end{array}$ & 1553 & $\begin{array}{l}\text { Lugdunum } \\
\text { Batavorum } \\
\text { Excud. Franc. } \\
\text { Gryphius } \\
\end{array}$ & decimosexto & $\begin{array}{l}\text { Erasmus } \\
(1466-1536)\end{array}$ \\
\hline $\begin{array}{l}\text { Novum Test. Gallic \& } \\
\text { Latine }\end{array}$ & 1561 & $\begin{array}{l}\text { Lugdunum } \\
\text { Per Guilliaume } \\
\text { Rouille }\end{array}$ & decimosexto & Sin datos \\
\hline Novum Test. Syriace & 1560 & $\begin{array}{l}\text { Antverpiae } \\
\text { Ex officina } \\
\text { Christophori Plantini }\end{array}$ & decimosexto & Sin datos \\
\hline
\end{tabular}

* El año correcto es 1569.

** La Biblia completa con sus anexos consta de 8 volúmenes. 


\section{Las Biblias de ARIas Montano y SANCTES Pagnino}

Sin duda, la Biblia más valiosa en poder de Juan Funguerio es la versión encargada por Felipe II al hebraísta Benito Arias Montano, llamada Regia o de Amberes, de la que solo conservaba en su biblioteca cuatro de los ocho volúmenes de la misma. Desconocemos si se trataba de los cuatro primeros, correspondientes al Antiguo Testamento, pero es posible suponerlo, teniendo en cuenta la formación en filología trilingüe de Funguerio ${ }^{44}$. Fue impresa en Amberes por Cristóbal Plantino ${ }^{45}$.

Inicialmente, se suponía que la Biblia Regia debía ser una segunda edición de la Políglota Complutense, impresa entre 1514-1520; pero se convirtió en otro proyecto intelectual de gran calado. De la Complutense se tomaron el texto hebreo y el griego de la versión de los Setenta para el Antiguo Testamento. Se incluyó el Tárgum arameo y la versión siriaca del Nuevo Testamento. El grupo de traductores trabajó además con la versión interlineal del erudito italiano Sanctes Pagnino ${ }^{46}$; se trataba de una traducción palabra a palabra desde el griego original, con un verdadero aparato bíblico con sus numerosas disertaciones sobre la Masorah, sobre los idiotismos hebreos, sobre el lenguaje arcaico, sobre pesos, medidas y monedas, sobre la geografía de Palestina, sobre arquitectura e indumentaria de los judíos, sobre la cronología, etc. ${ }^{47}$.

44 El contenido de sus ocho volúmenes de la Biblia Regia es el siguiente: volúmenes I al IV, Antiguo Testamento (proto y deuterocanónico), que incluye: el texto hebreo, el texto en latín de la Vulgata, el texto griego de la Septuaginta, con traducción latina, y el texto arameo de Targum de casi todos los libros del Antiguo Testamento, con traducción latina. La página de la izquierda tiene dos columnas con el hebreo original y la traducción al latín, la página de la derecha tiene el mismo texto en griego, con su propia traducción al latín. Por debajo de estas columnas hay una versión en arameo en la página de la izquierda y una traducción al latín de esta en el lado derecho. Cfr. José Luis Trullo, Arias Montano y la Biblia Regia, Sevilla, 2010, pp. 5-7.

45 Vid. Antonio Dávila PÉREZ, Correspondencia de Arias Montano conservada en el Museo PlantinMoretus de Amberes, Madrid, 2002.

46 Santes Pagnino (1470-1541), dominico experto en lenguas clásicas y orientales, como puede apreciarse por sus principales publicaciones: un curso completo de lengua griega titulado Isagoga graece, Aviñón, 1525; Enchiridion soepositionis vocabulorum Haruch, targum, Midrascim..., Hebraicae linguae aliisque libris apprime accommodum, ab auctore dicatum Francisco cardinali de Claromonte, París, 1530; Hebraicarum Institutionum libri quatuor, Sancte Pagnino Lucensi auctore ex Nobbi Kinchi priore porte fere transcrita, París, 1549. Además de estas obras de filología griega y hebrea, la más notable que dio al autor un renombre universal fue Veteris et novi testamenti nova translatio per Sanctem Pagninum nuper edita approbante Clemente VII, Lyon, 1527, utilizada por Benito Arias Montano.

47 Vid. Biblia hebraica. Eorundem latina interpretatio Xantis Pagnini Lucensis, recenter Benedicti Ariae Montani Hispal. et quorundam aliorum collato studio ad hebraicam dictionem diligentissime expensa. Acceserunt et huic editioni libri graece scripti qui uocantur Apocryphi cum interlineari interpretatione latina ex Bibliis Complutensibus petita. Antuerpiae, ex officina Christophori Plantini, 1584. 
La traducción fue realizada por Arias Montano, con la colaboración de un amplio equipo de expertos, como Francisco Raphelengius, yerno de Cristóbal Plantino, Nicolás y Guy Le Févre de la Boderie, Andreas Massius y los doctores de Lovaina Johannes Harlemius, Augustinus Hunnaeus, Cornelius Reyneri de Gouda. Prestaron también ayuda al proyecto los correctores Cornelio Kiel, Teodoro Kemps, Antonio Spitaels y los cardenales Espinosa, Granvela y Sirleto $^{48}$.

La Biblia Regia de Amberes tuvo inicialmente una acogida bastante fría en Roma, por el recelo hacia la supuesta tendencia hebraista de dicha versión, por las diferencias con respecto a la Biblia Políglota Complutense y, más aún, en relación con la Vulgata. Arias Montano logró la aprobación papal en 1572, tras superar la denuncia del biblista salmantino León de Castro ante la Inquisición, contando con la defensa del jesuita Juan de Mariana.

La tirada de la Biblia Regia fue de 1213 ejemplares. Como queda dicho, cabe plantearse cómo llegó a poseer varios tomos de esta valiosa edición, un personaje como Juan Funguerio, director de una escuela de gramática latina en la lejana Frisia. Se puede tener en cuenta que Cristóbal Plantino fue el impresor de la Biblia de Amberes y Funguerio era su cliente; pero no cabe aventurar si la compró, si le financió su adquisición alguno de sus mecenas frisones, o bien, fue un pago en especie a la revisión de pruebas de imprenta, tarea realizada por especialistas en lenguas bíblicas.

Además de la Biblia políglota de Amberes (1573) y la Biblia hebrea-latina de Sanctes Pagnino y Arias Montano (edición de 1609), caracterizadas por su excelencia lingüística y ortodoxia, Juan Funguerio poseía en su biblioteca otros volúmenes de la Sagrada Escritura de notables tipógrafos, vinculados a autores heterodoxos: es el caso de la Biblia latina anotada de Steelsius (1537) y la Biblia griega de Hervagius (1545) y la Biblia latina de Tornaesius (1590). De las dos primeras, el catálogo de la biblioteca fungueriana no indica su traductor, pero es posible rastrear su filiación religiosa. En el caso de Tornaesius, sabemos que fue una versión latina realizada por Franciscus Junius e Inmanuel Tremellius.

48 Vid. Francisco Calero Calero-Joaquín GonZÁlez MANZANARES, Tres aportaciones a la vida y obra de Benito Arias Montano, en José María MAESTRe MAESTRE, Eustaquio SánCHEZ SALOR, Manuel Antonio Díaz GiTo, Luis Charlo BrEA, Pedro Juan GaláN SÁNCHEZ (coords.), en Benito Arias Montano y los bumanistas de su tiempo, vol. 1, 2006, pp. 57-64. 


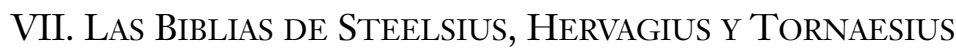

Johannes Steelsius, trabajó como librero y editor en Amberes entre 1533 y 1562. Casado con Margriete Hillen, hija del impresor Michael Hillenius, con la que tuvo tres hijos, uno de ellos, Frans, le sucedió al frente del negocio. En 1542 se casó en segundas nupcias con Anne van Ertborn, uno de los hijos, Gillis fue impresor, y tres hijas que se casaron con importantes impresores: Johanna con Petrus Bellerus, Maria con Arnout Coninx y Magdalena con Bernard Cordier.

En 1546 obtiene la licencia de impresor, aunque muchos de sus libros (unas trescientas treinta ediciones) fueron impresos por amigos suyos. Sin embargo, han llegado hasta nosotros algunos libros suyos impresos al heredar el taller de su suegro, algunos bellamente ilustrados. En 1559 ingresó como maestro librero en la Hermandad de san Lucas. Frecuentó las ferias de Francfort. Editó, sobre todo, libros religiosos, didácticos, autores clásicos y algún libro popular, en latín, francés y español; raramente lo hizo en neerlandés. Su viuda y herederos lo sucedieron en el negocio hasta $1576^{49}$.

En cinco ocasiones aparecen obras editadas por Steelsius en los Índices de la Universidad de Lovaina (1550 y 1558), incluyendo la Biblia anotada de 1537, impresa junto a Johannes Grapheus ${ }^{50}$.

Por su parte, Johannes Herwagen o Hervagius (ca. 1497-ca. 1559) era originario de tierras germánicas y estableció un taller de tipografía en Estrasburgo en torno a 1525 . Ha pasado a la historia por su edición de los Elementos de Euclides (1533) y de Padres de la Iglesia griegos. Publicó, además, otros libros, muchos de ellos de Lutero y otros autores reformados. Solicitó la colaboración de Martín Bucero, promotor de la reforma en Alsacia, para traducir al latín los comentarios de Lutero al Nuevo Testamento, que no fueron del agrado del autor.

En 1528 obtuvo la ciudadanía en Basilea y se casó con Gertrude Lachner, viuda del conocido impresor Johann Froben, impresor y amigo de Erasmo. Junto con el hijo (Hieronymus Froben) y el yerno (Nicolaus Episcopius) de aquel se hizo cargo de su imprenta, donde publicaron conjuntamente libros de Erasmo, de la patrística griega y de literatura clásica en su officina hervagiana. Obtuvo de Carlos V, el título de caballero y el permiso de publicar con privilegio del emperador ${ }^{51}$.

49 Cfr. Anne RouZET, Dictionnaire des imprimeurs, libraires et éditeurs belges des XVe et XVI siècles dans les limites géographiques de la Belgique actuelle, Nieuwkoop, 1975, pp. 207-208.

50 Cfr. Jesús Martínez De Bujanda (dir.), Léon-Ernest Halkin, René DaVIGNON, Patrick PasTURE, Ela STANEK, Index de l'Université de Louvain, 1546, 1550, 1558, vol. 2, Gèneve, 1986, p. 110.

51 Cfr. Thomas Brian Deutscher (ed.), Contemporaries of Erasmus: A Biographical Register of the Renaissance and Reformation, Toronto, 2003, pp. 186-187. 
Su Biblia Graeca data de 1545 y fue prologada por Melanchthon ${ }^{52}$. Para el Antiguo Testamento, en algunas ediciones, sigue la de Aldo Manuzio de 1518; en otras, la realizada en Estrasburgo en 1526 por Fabricius Cephalaeus (Wolfgang Köpfel), impresor cercano a la reforma luterana, y la versión griega de la políglota Complutense. Para el Nuevo Testamento utilizó la quinta edición de Erasmo, publicado por Froben en Basilea ${ }^{53}$. Fue nuevamente impresa en 1548 con bellos dibujos y letras ornamentadas, incluyendo una biografía de cada evangelista y los Evangelios apócrifos ${ }^{54}$. Fue incluido en el Index romano y en el hispano por su vinculación con Melanchthon y Erasmo ${ }^{55}$.

La Biblia Sacra Latina recens ex Hebraeo facta, brevibusque scholi[i]s illustrata ab I. Tremellio \& F. Iunio, cum Indice ad Notas $V$. T. fue publicada en 1590 por Jean de Tournes (1504-1564) impresor y librero nacido en Lyon, establecido en Ginebra en el taller de los herederos de Andreas Wecheli. Tournes se había formado en la imprenta de Sebastian Gryphius, al que se hará mención más adelante, abrazó el calvinismo hacia 1545 y se refugió en Ginebra al iniciarse en Francia la persecución contra los hugonotes. Los autores de esta versión son, en realidad, tres: la versión latina y anotada del Antiguo Testamento a partir del hebreo y siriaco fue realizada por el judeoconverso italiano Inmanuel Tremellius y el francés Franciscus Junius el Viejo, ambos autores reformados ${ }^{56}$. El Nuevo Testamento reproduce una versión latina, a partir del original griego, de Theodoro Beza, al que se hará referencia más abajo. Tremellius (1510-1580) fue profesor de hebreo en Cambridge, Heidelberg y Sedan. Junius (1545-1602), era coetáneo de Juan Funguerio, se formó en la Academia de Ginebra, fue capellán del calvinista Guiller-

52 Vid. Juan Luis MONREAl PÉREZ, La contribución de Philipp Melanchthon, Praeceptor Germaniae, a la lengua y la enseñanza, entre la cultura bumanista y la reforma alemana, en Historia de la Educación. Revista interuniversitaria, 36 (2017), pp. 207-228.

53 Cfr. Jacob LE LONG y Christianus Fridericus BOERNERUS, Bibliotheca sacra: seu syllabus omnium ferme sacrae scripturae editionum ac versionum secundum seriem linguarum, quibus vulgatae sunt, notis historicis et criticis illustratus adjunctis praestantissimis codd. msc [...] Totum opus cum additamentis, suo loco in nova hac editione collocatis, recensuit \& castigavit, novis praeterea editionibus, versionibus cod mss. notisque auxit Christianus Fridericus Boernerus, Lipsiae, 1709, p. 460.

54 Cfr.Thomas Frognall DiBdin, An Introduction to the Knowledge of Rare and Valuable Editions of the Greek and Latin Classics. Together with an Account of Polyglot Bibles, Polyglot Psalters, Hebrew Bibles, Greek Bibles and Greek Testaments, the Greek Fathers, and the Latin Fathers, vol. 1, London, 1827, p. 86.

55 Por ejemplo, en el Index librorum probibitorum et expurgandorum novissimus: pro catholicis Hispaniarum regnis Philippi IV regis cathol. Ex typographaeo Didaci Diaz, Matriti, 1667, p.612.

56 Sobre Tremellius, vid. Kenneth AusTIN, From fudaism to Calvinism: The Life and Writings of Immanuel Tremellius (c.1510-1580), Routledge, 2016. 
mo de Orange e impartió clases en Heidelberg ${ }^{57}$. La Biblia de Junius-Tremellius fue reeditada profusamente hasta finales del siglo XVII ${ }^{58}$.

Funguerio también poseía otra Biblia hebrea (Totum Vetus Testamentum vel Biblia Hebraicè) en 4 volúmenes, formato decimosexto, de la que no hay más datos sobre impresor, año y plaza de impresión, además de dos publicaciones bíblicas en lengua vernácula (neerlandés y francés) ya citadas.

\section{El NueVo TESTAMENTO EN LA BIBLIOTECA FUNGUERIANA}

Algunos de los autores de versiones del Nuevo Testamento que se hallaban en la biblioteca fungueriana fueron considerados por la Iglesia romana más o menos cercanos a la heterodoxia: es el caso de Valla, Erasmo y Beza, vedados por motivos en parte comunes y, en parte, distintos ${ }^{59}$.

El In Novum Testamentum ex diversorum utriusque linguae codicum collatione adnotationes de Lorenzo Valla (1405-1457) fue la base de la crítica textual de humanistas posteriores, como Erasmo de Róterdam, que se encargó de publicarlo en $1505^{60}$. La edición en poder de Funguerio incluía la obra completa de Valla, en tamaño folio, incluyendo el citado Novum Testamentum ${ }^{61}$. El Index romano de 1564 incluyó algunas de las obras más conocidas de Valla: Sobre la falsedad de la donación de Constantino, De voluptate y De libero arbitrio. El impresor de esta edición de Valla fue Henricus Petrus (1508-1579) de Basilea. En su officina benricpetrina también vieron la luz algunas obras de Copérnico y la Cosmografía de Sebastian Münster.

El príncipe de los humanistas preparó su propia versión latina del original griego del Nuevo Testamento, publicada por Johann Froben en Basilea en $1516^{62}$. La

57 Tremellius aparece en el Índice hispano como autor de primera clase. Cfr. Index librorum probibitorum et expurgandorum novissimus, op. cit., p. 213.

58 Cfr. Jacob LE LONG y Christianus Fridericus BOERNERUS, Bibliotheca sacra: seu syllabus omnium ferme sacrae scripturae editionum, op. cit., p. 468.

59 Se sigue un orden cronológico de autores, no el del catálogo de la biblioteca fungueriana

60 Vid. Mariangela RegOLIOSI, Lorenzo Valla e la Riforma del XVI secolo, en Studia Philologica Valentina, vol. 10/7 (2007), pp. 25-45.

61 Vid. CORNELIA LINDE, Lorenzo Valla and the authenticity of Sacred Texts, en Humanistica lovaniensia: journal of neo-latin studies, 60 (2011), pp. 35-63.

62 Joannes Frobenius (ca.1460-1527) impresor de Basilea, amigo y editor de Erasmo. Contó con la colaboración de Hans Holbein, el joven, en las ilustraciones de sus libros. Su negocio encontró continuidad en su hijo Jerónimo y su nieto Ambrosio. Vid. Valentina SEBASTIANI, Fohann Froben: Printer of Basel: A Biographical Profile and Catalogue of His Editions, Leiden, 2018, pp. 70-77. 
versión erasmiana fue tenida en cuenta, a su vez, por Lutero para su traducción al alemán. Sin embargo, esta primera edición suscitó ciertas críticas por la inexactitud de algunos pasajes. El traductor revisó las siguientes ediciones $(1522,1527,1535)$. La cuarta edición data de 1542, cuando Erasmo ya había muerto y se imprimió con dos textos paralelos: la versión griega Complutense y la Vulgata latina. Posteriormente, fue reeditada en otras muchas imprentas centroeuropeas ${ }^{63}$. En el Index de 1564 aparece Erasmo como autor de primera clase, es decir, como escritor con obras que están prohibidas mientras no sean revisadas y expurgadas.

La edición griego-latín del Nuevo Testamento de la biblioteca fungueriana no es de Froben, sino muy posterior: data de 1553 y se debe al tipógrafo Franciscus Gryphius. Este era de origen alemán, pero es conocido por su taller parisino, en el que trabajó entre 1532 y 1552, junto a su hermano Sebastian y su hijo Antoine. En París, Gryphius editó una Biblia (1541) incluida en los Índices de Lovaina de 1550 y 1558. Además, su nombre se halla en el Index romano de 1564, por el hecho de haber publicado algunas obras de Savonarola. Al retirarse, se trasladó a los Países Bajos y parece que realizó algunos trabajos en Leiden, donde apareció en 1553 esta versión de Erasmo ${ }^{64}$.

Otro ejemplar notable de la biblioteca fungueriana se debe a un coetáneo suyo, el helenista e impresor galo Henri Estienn (Henricus Stephanus) (ca.15281598). Hijo del humanista y tipógrafo Robert Estienn, conocido por sus cuidadas ediciones bíblicas y la división de sus capítulos en versículos. Su hijo Henricus trabajó en Venecia bajo las órdenes de Aldo Manuzio, que fue su mentor y contó con la financiación del banquero y mecenas Ulrico Fugger para algunos de sus proyectos.

Entre 1550 y 1555, Henricus publicó en París varias reediciones del Nuevo Testamento griego-latino de Teodoro Beza (1519-1605), sucesor de Calvino en el gobierno de Ginebra, acompañado en columnas paralelas del texto de la Vulgata y en anexos, un resumen de las propuestas religiosas calvinistas (cum quibusdam Symbolis in fine additis) ${ }^{65}$. Tanto Calvino como Beza fueron considerados heresiarcas en el Index librorum Probibutorum.

63 Vid. Thomas Frognall DibDIN, An Introduction to the Knowledge of Rare and Valuable Editions of the Greek and Latin Classics, op. cit., pp. 106-111.

64 Vid. Inmaculada DELGADO JARA, El texto griego y la traducción latina del Nuevo Testamento de Erasmo (1516), en Miguel Anxo PENA GonZÁLEZ y Inmaculada DELGado JaRA (coords.), Revolución en el Humanismo cristiano, op. cit., pp. 43-70.

65 Cfr. Thomas Frognall Dibdin, An Introduction to the Knowledge of Rare and Valuable Editions of the Greek and Latin Classics, op. cit., p. 125. 
Además, Funguerio era propietario de un Nouveau Testament editado en La Rochelle (Francia) en 1591, en octavo ${ }^{66}$; es muy posible que este último fuera impreso por Jêrome Haultin (ca. 1565-1600), sobrino y aprendiz de Pierre-André Haultin, dueño de la imprenta calvinista más famosa en suelo francés ${ }^{67}$.

Entre los libros de la biblioteca fungueriana se encuentra también un Novum Testamentum Gallice \&Latine (1561), publicado por Guillaume Rouillé en Lyon; un Novum Testamentum Syriaece, impreso por Cristóbal Plantino en Amberes en 1560 y un Novum Testamentum Graece, cum Indice, sin fecha, editado por Johannes Oporinus en Basilea, ambos en decimosexto.

Los trabajos de Plantino son muy conocidos, pero Rouillé y Oporinus gozaron también de fama y buena clientela. Como muchos impresores de entonces, tanto el francés Rouillé (1518-1589) como el helvético Oporinus (1507-1568) tuvieron una notable formación profesional: el primero fue aprendiz en Venecia de Giolito de Ferrari y el segundo trabajó en el taller de Froben en Basilea y era hijo del pintor Hans Herbst.

Guillame Rouillé se estableció en Lyon hacia 1544 y se casó con la hija del librero italiano Domenico de Portinaris. Editó libros en latín, francés e italiano. Tuvo una sucursal en París regentada por su sobrino Philippe. Fue concejal municipal de la capital de Auvernia. Aunque hacia 1560 se aproximó a posturas reformadas, fue considerado un buen católico al final de su vida ${ }^{68}$.

Por su parte, Oporinus, se cultivó como humanista, estudió latín, griego y medicina: fue discípulo de Paracelso. Entre sus obras más destacadas se encuentra una traducción latina del Corán, hecho que levantó una notable polémica; además, publicó trabajos del médico Andreas Vesalius y del historiador reformado Matías Flacius.

Es posible rastrear la referencia bibliográfica de esta edición; según Frognall Dibdin, Oporinus publicó en 1552 un Novum Testamentum Graece, cum Indice, en dos volúmenes, basado en la realizada por Tedoro Beza e impresa por Henricus Stephanus ${ }^{69}$.

66 Cfr. Andrew Pettegree-Malcolm Walsby-Alexander WiLkinson, French Vernacular Books: Books Published in the French Language before 1601, vol. 1, Leiden, 2007, p. 186.

67 Cfr. Hendrik Désiré Louis VerVLIET, The Palaeotypography of the French Renaissance: Selected Papers on Sixteenth-century Typefaces, vol. 1, Leiden, 2008, p. 247.

68 Cfr, Henri \& Julien BAUDRIER, Bibliographie lyonnaise: recherches sur les imprimeurs, libraires, relieurs et fondeurs de lettres de Lyon au XVIe siècle, vol. 9, Genève, 1999, pp. 277-278.

69 Cfr.Thomas Frognall DibDin, An Introduction to the Knowledge of Rare and Valuable Editions of the Greek and Latin Classics, op. cit., p.123. 


\section{CONCLUSIONES}

Todo parece indicar que la biblioteca privada de Juan Funguerio era la propia de un humanista del norte, un cristiano reformado, con amplios intereses intelectuales. El presente estudio ha tratado de describir el contenido de esta biblioteca, compuesta por unos 1155 títulos y vendida en subasta pública en Leiden en 1613, al año siguiente de la muerte del dueño.

Se hace referencia especial a la proporción de libros teológicos y a los ejemplares de la Sagrada Escritura, con el fin de comprobar la penetración de las doctrinas reformadas en un bibliófilo calvinista de la primera hora. Para contextualizar el objeto de estas líneas, se ha expuesto someramente la situación en el norte de los Países Bajos, tras la independencia de la Corona hispana y las corrientes religiosas nacidas en dicho ámbito.

Se ha podido comprobar que Juan Funguerio poseía 208 títulos sobre temas teológicos, que equivalen al $18 \%$ del total de su biblioteca. Del recuento y clasificación de dichos volúmenes, se puede colegir que los libros de Funguerio se corresponden con el perfil de un humanista reformado: su interés por la Sagrada Escritura (15 títulos) y los Padres de la Iglesia (31 títulos), el volumen de libros de autores reformados (115 títulos) y su escaso aprecio por ámbito medieval ( 9 títulos) y católico coetáneo (38 títulos), resultan reveladores sobre su identidad cultural y religiosa.

Antes de morir, el humanista tenía en su haber, seis Biblias completas, un Antiguo Testamento y seis versiones del Nuevo Testamento, datados en un arco de tiempo de edición amplio (entre 1537 y 1609).

Salvo los volúmenes correspondientes a la Biblia Regia de Amberes que, sin duda, era la edición más valiosa y ortodoxa, desde el punto de vista lingüístico y doctrinal, Juan Funguerio tuvo en su biblioteca personal ediciones bíblicas incluidas en los Índices de libros probibidos de Lovaina, Roma y territorios hispanos (editadas por Steelsius, Hervagius y Tornaesius). Además, poseía dos Biblias en lenguas vernáculas (neerlandés y francés) claro signo de su asimilación a posturas reformadas. Respecto a las versiones del Nuevo Testamento, las de su propiedad fueron realizadas por autores o editores controvertidos (Valla, Erasmo, Henri Estienn) o cercanos a la reforma (Rouillé y Oporinus). 


\section{FUENTES Y BIBLIOGRAFÍA}

\section{Fuentes}

CALVINO, Juan, Institución de la religión cristiana, compuesta en quatro libros, y dividida en capitul s por Iuan Calvino. Y abora nuevamente traduzida en romance castellano, por Cypriano de Valera, Londres, 1597.

Cremius, Thomas, De Eruditione Comparanda In Humanioribus, Vita, Studio Politico, Cognitione Auctorum Ecclesiasticorum, Historicorum, Politicorum ac Militarium, item Peregrinatione tractatus. Foach. Camerarii, Foh. Fungeri, Arn. Clapmarii, Lugduni Batavorum, 1699.

Desselius, Valerius Andreas, Fasti Academici Studii Generalis Lovainensis, Lovainii, 1635.

Frognall DibDIN, Thomas, An Introduction to the Knowledge of Rare and Valuable Editions of the Greek and Latin Classics. Together with an Account of Polyglot Bibles, Polyglot Psalters, Hebrew Bibles, Greek Bibles and Greek Testaments, the Greek Fathers, and the Latin Fathers, vol. 1, London, 1827.

GHero, Ranutio, Delitiae Centum Poetarum Belgicorum, Francoforte, 1614.

Index librorum probibitorum et expurgandorum novissimus: pro catholicis Hispaniarum regnis Philippi IV regis cathol. Ex typographaeo Didaci Diaz, Matriti, 1667.

LE LONG, Jacoby y BOERNERUS, Christianus Fridericus, Bibliotheca sacra: seu syllabus omnium ferme sacrae scripturae editionum ac versionum secundum seriem linguarum, quibus vulgatae sunt, notis historicis et criticis illustratus adjunctis praestantissimis codd. msc [...] Totum opus cum additamentis, suo loco in nova hac editione collocatis, recensuit of castigavit, novis praeterea editionibus, versionibus cod mss. notisque auxit Christianus Fridericus Boernerus, Lipsiae, 1709.

Molhuysen, Philip Christian y BLOK, Petrus Johannes, Nieuw Nederlandschbiografisch woordenboek, Leiden, 1918.

Neerlandia catbólica seu provinciae ultrajectencis historia et cognitio, Utrecht, 1887.

SAXIUS, Christopher, Onomasticon literarium, t.3, Traiecti ad Rhenum, 1784.

SwEERTIUS, Franciscus, Athenae Belgicae sive Nomenclator infer. Germaniae scriptorvm, qvi disciplinas philologicas, philosophicas, theologicas, ivridicas, medicas et mosicas illostraront, Antuerpiae, 1628.

VAN DER AA, Abraham Jacob, Biographischwoordenboek der Nederlanden, t. 6, Haarlem, 18521878.

\section{Fuentes en formato digital}

Bibliopolis Website van de Koninklijke Bibliotheek te Den Haag over de geschiedenis van de boekdrukkunst in Nederland (Página web de la Biblioteca Real de La Haya sobre la historia de la imprenta en los Países Bajos): http://www.bibliopolis.nl/

Conclusiones de los sinodos de Emden y Dordrecht en castellano:

http://www.iglesiapueblonuevo.es/index.php? codigo=enc_reformadah\#dos

Kongelige Bibliotek Kopenhagen (Biblioteca Nacional de Dinamarca), ms. 79 II 29.

Veilingcatalogus bibliotheek Johannes Fungeri, 1613 (Catálogo de la subasta de la biblioteca de Juan Funguerio) 
http://www.mpaginae.nl/At/Fungeruslinks.htm

Textos de la Confesión belga y del Catecismo de Heidelberg en castellano:

http://www.iglesiapueblonuevo.es/index.php?codigo=historiap182

http://www.iglesiapueblonuevo.es/index.php?codigo=historiap181

\section{Referencias bibliográficas}

AKKerman, Fokke; VANDERJaGT, Arjo y VAN DER LAAN, Adrie (eds.), Northern Humanism in European Context, 1469-1625: From the Adwert Academy to Ubbo Emmius, Leiden, 1999.

AUsTIN, Kenneth, From Judaism to Calvinism: The Life and Writings of Immanuel Tremellius (c.1510-1580), Routledge, 2016.

BAUDRIER, Henri\&Julien, Bibliographie lyonnaise: recherches sur les imprimeurs, libraires, relieurs et fondeurs de lettres de Lyon au XVIe siècle, vol. 9, Genève, 1999.

BÉCAREs Botas, Vicente, Los libros y las lecturas del humanista, en Silva: Estudios de bumanismo y tradición clásica, 2 (2003), pp. 9-26.

BOEKHOLT, Petrus Theodorus y DE BOOY, Engelina, Geschiedenis van de school in Nederland vanaf de middeleeuwen tot aan de huidige tijd' door, Assen-Maastricht, 1987.

Calero Calero, Francisco y González MANZANAREs, Joaquín, Tres aportaciones a la vida y obra de Benito Arias Montano, en José María MAESTRE MAestre, Eustaquio SÁnCHEZ SAlor, Manuel Antonio Díaz Gito, Luis Charlo Brea, Pedro Juan Galán Sánchez (coords.), Benito Arias Montano y los humanistas de su tiempo, vol. 1, 2006.

Checa Cremades, José Luis, Encuadernación. Doce ensayos sobre bibliofilia y artes del libro (siglos XIV-XXI), vol. 1, Madrid, 2012.

LINDE, Cornelia, Lorenzo Valla and the authenticity of Sacred Texts, en Humanistica lovaniensia: journal of neo-latin studies, 60 (2011), pp. 35-63.

DÁvILA PÉREZ, Antonio, Correspondencia de Arias Montano conservada en el Museo Plantin-Moretus de Amberes, Madrid, 2002.

DELGADO JARA, Inmaculada, El texto griego y la traducción latina del Nuevo Testamento de Erasmo (1516), en Miguel Anxo Pena González y Inmaculada Delgado Jara (coords.), Revolución en el humanismo cristiano: La edición de Erasmo del Nuevo Testamento (1516), Salamanca, 2016.

Deutscher, Thomas Brian (ed.), Contemporaries of Erasmus: A Biographical Register of the Renaissance and Reformation, Toronto, 2003.

FUNGUERIO, Juan, De puerorum disciplina et recta educatione liber, estudio preliminar de COMELLA-GUTIÉRREZ, Beatriz; texto bilingüe latín-castellano y notas a cargo de RODRÍGUEZ GARCÍA, Virgilio, Madrid, 2018.

GALENDE DÍAZ, Juan Carlos, Las bibliotecas de los humanistas y el Renacimiento, en Revista general de información y documentación, 6 (1996/2), pp. 91-123.

GARCÍA AlONSO, Marta, Una ética para los cristianos: el fundamento biblico de la moral calvinista, en Revista Española de filosofía Medieval, 13 (2006), pp. 165-180.

García Moreno, Antonio, La Biblia en torno a Trento, en Scripta Theologica, 15/2 (1983), pp. 567-585. 
- San ferónimo, traductor paradigmático, en Scripta Theologica, 11/3 (1979), pp. 889-928.

Grendler, Paul F., Renassaince Education between Religion and Politics, Aldershot, 2006.

HAYE, Thomas, Humanismus im Norden: frühneuzeitliche Rezeption antiker Kultur und Literatur an Nord-und Ostsee, Amsterdam, 2000.

HeEsaKkers, Christian L., La difusión del bumanismo en los Países Bajos: desde Erasmo hasta la fundación de las primeras universidades holandesas, en Ferrán GRAU CODINA (coord.), en La Universitat de València i l'bumanisme: Studia humanitatis i renovació cultural a Europa i el nou món, Valencia, 2003.

Janssen, Geert H., The dutchness of the Dutch Golden Age, en The Historical Fournal, 53/3 (2010), pp. 805-817.

LIMÓN, Francisco (ed.), Introducción a la Historia de la Iglesia reformada, Florida, 2012.

LINDSAY, Thomas Martin, La Reforma y su desarrollo social, Barcelona, 1986.

MARTÍNEZ DE Bujanda, Jesús (dir.), Index de l'Université de Louvain, 1546, 1550 , 1558, vol. 2, Gèneve, 1986.

Monreal PÉRez, Juan Luis, La contribución de Philipp Melanchthon, Praeceptor Germaniae, a la lengua y la enseñanza, entre la cultura humanista y la reforma alemana, en Historia de la Educación. Revista interuniversitaria, 36 (2017), pp. 207-228.

NEgrín FAJARDO, Olegario, Fuentes para el estudio del bumanismo pedagógico en Europa, en Historia de la educación: Revista interuniversitaria, 31 (2012), pp. 319-338.

Nyenhuis, Gerald, Comentario del Catecismo de Heidelberg, México D.F., 2004.

PARKER, Charles H., Faith on the margins: catholics and Catholicism in Dutch golden age, Massachusetts, 2008.

PetTegree, Andrew, Walsby, Malcolm y WiLKInSOn, Alexander, French Vernacular Books: Books Published in the French Language before 1601, vol. 1, Leiden, 2007.

ROUZET, Anne, Dictionnaire des imprimeurs, libraires et éditeurs belges des XVe et XVIe siècles dans les limites géographiques de la Belgique actuelle, Nieuwkoop, 1975.

SCHAFF, Philippe, The creeds of Christendom, Michigan, 1931.

Sebastiani, Valentina, Johann Froben: Printer of Basel: A Biographical Profile and Catalogue of His Editions, Leiden, 2018.

SELDERHUIS, Herman (ed.), Handbook of Dutch Chruch History, Göttingen, 2014.

Trueman, Carl R., The Reception of Calvin: Historical Considerations, en Church History and Religious Culture 91 (2011)

VAN TIL, Henry, The Calvinistic Concept of Culture, Michigan, 2001.

VERGARA CIORDIA, Javier, Las obras pedagógicas del humanismo erasmista, en PEÑA GONZÁLEZ, Miguel Anxo y Delgado JARA, Inmaculada (coords.), Revolución en el humanismo cristiano: La edición de Erasmo del Nuevo Testamento (1516), Salamanca, 2016.

VERVLIET, Hendrik Désiré Louis, The Palaeotypography of the French Renaissance: Selected Papers on Sixteenth-century Typefaces, vol. 1, Leiden, 2008. 
0000 